\title{
Correction to: Rouxiella aceris sp. nov., isolated from tree sap and the emended description of the genus Rouxiella
}

\author{
Soon Dong Lee $\mathbb{D}$ - Hong Lim Yang • In Seop Kim
}

Published online: 25 August 2021

(C) Springer Nature Switzerland AG 2021

\section{Correction to: \\ Antonie van Leeuwenhoek (2021) 114:1013-1024 \\ https://doi.org/10.1007/s10482-021-01572-0}

In the original publication of the article by Lee, Yang and Kim published in Antonie van Leeuwenhoek (2021) 114:1013-1024, the sentence 'Type strain $\mathrm{SAP}^{-1}{ }^{\mathrm{T}} \quad\left(=\mathrm{KCTC} \quad 72599^{\mathrm{T}}=\mathrm{CCM} \quad 9078^{\mathrm{T}}\right)$ was isolated from tree sap drawn from Acer pictum in Mt. Halla in Jeju, Republic of Korea.' should be changed to the sentence 'Type strain $\mathrm{SAP}-1^{\mathrm{T}}$ $\left(=\right.$ KCTC $72959^{\mathrm{T}}=$ CCM $\left.9078^{\mathrm{T}}\right)$ was isolated from tree sap drawn from Acer pictum in Mt. Halla in Jeju, Republic of Korea.' in the 'Description of

The original article can be found online at https:// doi.org/10.1007/s10482-021-01572-0.

S. D. Lee $(\bowtie)$

Institute of Jeju Microbial Resources, BioPS Co., Ltd, Jeju 63243, Republic of Korea

e-mail: sd.lee@biops.co.kr

\section{H. L. Yang}

Institute of Hallasan Ecology and Culture, Jeju 63064, Republic of Korea

\section{S. Kim}

Department of Biological Sciences and Biotechnology, Hannam University, Daejon 34054, Republic of Korea
Rouxiella aceris sp. nov.' on 30th line of the right column of page 1021.

The sentence in 'Description of Rouxiella aceris sp. nov.' should have read:

Description of Rouxiella aceris sp. nov.

Rouxiella aceris (a'ce.ris. L. gen. n. aceris of Acer, isolated from sap of Acer pictum Thunb.).

Cells are Gram-reaction-negative, facultatively anaerobic, short rods $(0.6-0.9 \times 1.1-1.4 \mu \mathrm{m})$ and motile by means of a polar flagellum. Catalasepositive and oxidase-nagative. Colonies are white in colour, circular, convex with entire margin and reaches $0.5-1.5 \mathrm{~mm}$ in diameter after incubation for 2 days on NA at $30{ }^{\circ} \mathrm{C}$. Good growth occurs on NA, R2A and TSA. Growth occurs at $4-37{ }^{\circ} \mathrm{C}$ (optimum, 25-30 ${ }^{\circ} \mathrm{C}$ ) and $\mathrm{pH} 5.0-9.0$ (optimum, $\mathrm{pH} 7.0$ ). Growth occurs in the presence of $0-6 \%(\mathrm{w} / \mathrm{v}) \mathrm{NaCl}$ (optimum, $1 \%)$. Nitrate is reduced to nitrite. Aesculin hydrolysis and glucose fermentation is observed. Assimilates $N$ acetyl-D-glucosamine, D-arabinose, D-glucose, D-maltose, D-mannitol, D-mannose, citrate, gluconate and malate. Alkaline phosphatase, esterase (C4) (weak), esterase lipase (C8), leucine arylamidase, acid phosphatase, naphthol-AS-BI-phosphohydrolase, $\alpha$-galactosidase, $\quad \beta$-galactosidase, and $\quad N$-acetyl- $\beta$ glucosaminidase are present. Activity of $\beta$-glucosidase is variable depending on strains. Acid is produced 
from glycerol, L-arabinose, D-ribose, D-xylose, Dgalactose, D-glucose, D-fructose, D-mannose, D-mannitol, sorbitol, $\mathrm{N}$-acetylglucosamine, D-melibiose, sucrose, raffinose, gentibiose, D-arabitol, gluconate and 5-ketogluconate. Acid production from amygdalin, arbutin, D-maltose rhamnose and salicin is variable depending on strains. The major isoprenoid quinone is Q-8. The predominant fatty acids are $\mathrm{C}_{16: 0 \text {, }}$ $\mathrm{C}_{17: 0}$ cyclo, summed feature $3\left(\mathrm{C}_{16: 1} \omega 7 \mathrm{c}\right.$ and/or $\left.\mathrm{C}_{16: 1} \omega 6 \mathrm{c}\right)$ and $\mathrm{C}_{18: 1} \omega 7 \mathrm{c}$. The polar lipids consist of phosphatidylethanolamine, phosphatidylglycerol and an unidentified aminophospholipid. The $\mathrm{G}+\mathrm{C}$ content of the genomic DNA is $51.3 \%$.

Type strain $\mathrm{SAP}^{-1}{ }^{\mathrm{T}}\left(=\mathrm{KCTC} 72959^{\mathrm{T}}=\mathrm{CCM}\right.$ $9078^{\mathrm{T}}$ ) was isolated from tree sap drawn from Acer pictum in Mt. Halla in Jeju, Republic of Korea. The type strain does not produce acid from amygdalin, arbutin, D-maltose, rhamnose or salicin, and possesses $\beta$-glucosidase activity. The DDBJ/ENA/GenBank accession numbers of the 16S rRNA gene and genome sequences for strain $\mathrm{SAP}-1^{\mathrm{T}}$ are MN737199 and JAADJU010000000, respectively.

We apologize for any inconvenience that this may have caused.

Publisher's Note Springer Nature remains neutral with regard to jurisdictional claims in published maps and institutional affiliations. 